Article

\title{
Correction for the Impact of the Surface Characteristics on the Estimation of the Effective Emissivity at Fine Resolution in Urban Areas
}

\author{
Laure Roupioz * (D), Françoise Nerry and Jérôme Colin \\ ICube Laboratory, UMR 7357 CNRS-University of Strasbourg, 300 bd Sebastien Brant, CS 10413, \\ F-67412 Illkirch CEDEX, France; f.nerry@unistra.fr (F.N.); j.colin@unistra.fr (J.C.) \\ * Correspondence: laure.roupioz@onera.fr; Tel.: +33-562-252-883
}

Received: 27 February 2018; Accepted: 4 May 2018; Published: 11 May 2018

\begin{abstract}
Most of the methods used to retrieve land surface temperature (LST) from thermal infrared (TIR) satellite data in urban areas do not take into account the complexity of the surface. Cities are characterized by high surface roughness and one of the main constraints to estimate LST over those areas is the difficulty to define an effective emissivity for a given pixel at a given scale. When working with mixed pixels, the emissivity used to estimate the LST is an effective emissivity composed of the emissivities of each basic element constituting the pixel. In urban areas, the surface geometry has a strong impact on this effective emissivity. Its estimation from TIR satellite data must be carried out considering multiple surface reflections and diffusions within the urban canopy in order to retrieve accurate LST values. The objective of this study is then to evaluate the impact of the surface geometry within the pixel on effective emissivity estimation and to propose a method to derive an effective emissivity corrected for those effects. Emissivity can be derived at $90 \mathrm{~m}$ of spatial resolution from the TIR data acquired by ASTER. To evaluate the impact of the geometry at the scale of an ASTER pixel, several urban canyon configurations are designed to develop and test the correction method. The basic principle behind the method is to accurately estimate the downwelling TIR radiation received by a pixel integrating contributions from both the atmosphere and the scene inside this pixel and then derive the corrected effective emissivity from ASTER data using the TES (temperature emissivity separation) algorithm. First, the total downwelling TIR radiation is estimated from the geometric characteristics of the scene, using morphological indicators and integrating the non-isothermal behavior of the pixel thanks to 3D thermo-radiative model simulations. The validation of those estimations for each canyon configuration provides a maximum RMSE (Root Mean Square Error) value of $2.2 \mathrm{~W} \cdot \mathrm{m}^{-2}$. The validation performed over a district extracted from the 3D numerical model of Strasbourg (France) shows a RMSE of $2.5 \mathrm{~W} \cdot \mathrm{m}^{-2}$. Once the method to estimate the total downwelling TIR radiation is validated, LSE and LST maps are retrieved from an ASTER image over three districts of Strasbourg, showing that accounting for the surface geometry highlights thermal behavior differences inside districts, and that the impact of the geometry seems more influenced by building height than street width or building density.
\end{abstract}

Keywords: effective emissivity; surface roughness; urban areas; thermal infrared satellite data

\section{Introduction}

The growing trend towards urbanization raises a number of issues such as deteriorating air quality or rising temperatures [1,2]. The adaptation of cities to climate change has become necessary and many actions are currently carried out in order to understand and improve the comfort and quality of life in urban areas. However, the effectiveness of the implemented or planned actions must be 
quantified to evaluate their relevance and performance. To that purpose, several studies highlighted the potential of satellite remote sensing, each image providing instantaneous snapshots of an entire urban area [3-8]. Those studies mainly deal with the urban heat island phenomenon and strongly rely on the estimation of land surface temperature (LST) and emissivity (LSE) from different thermal infrared (TIR) space borne sensors.

The finest spatial resolution offered by the current TIR sensors, such as ASTER (asterweb.jpl. nasa.gov) or Landsat (landsat.usgs.gov), is about $100 \mathrm{~m}$, which is considered as sufficient to represent most intraurban temperature variations for urban climate studies [9]. At this scale, each pixel is a mixture of different urban elements such as buildings, streets, courtyards or squares, and its surface is then characterized by a strong roughness. This surface complexity inside the pixels is one of the main obstacles to the accurate retrieval of the LST [10-15] and is often neglected when working over urban areas. When dealing with mixed pixels, the estimation of the LST requires the use of an effective emissivity, depending on the emissivity of each component of the pixel. In cities, this effective emissivity is strongly influenced by the surface geometry and its estimation must be carried out by integrating the emission and multiple reflections of the urban canopy. It is crucial to derive a correct effective emissivity to accurately estimate LST from TIR satellite data over urban areas. Currently, LST and LSE data products are operationally derived at $90 \mathrm{~m}$ spatial resolution from ASTER data using the TES (temperature emissivity separation) algorithm [16]. Although this method provides satisfying results in most cases $[17,18]$, it does not take into account the complexity of the surface over urban areas while the surface geometry was identified as one of the factors of error [18]. The objective of the study is then to address the issue of geometry within the pixel by investigating the impact of this geometry on the surface emissivity and temperature retrieved using TES and to propose a method to correct for those geometric effects.

The TES requires two inputs: the surface-leaving radiance measured in the five TIR bands of ASTER and the corresponding downwelling sky irradiance for each band, currently simulated as the top-of-canopy TIR radiation coming from the atmosphere using MODTRAN [19]. The idea is to improve the estimations of the TES by providing better estimates of its inputs, in this case the downwelling TIR radiation taking into account the geometry within the pixel. To do so, the impact of the surface geometry is integrated into the estimation of the downwelling TIR radiation for each pixel by taking into account all contributions, namely radiation coming from the atmosphere, radiation emitted by the surrounding elements, and radiation from multiple reflections in the scene inside the pixels. This total downwelling TIR radiation can be estimated precisely using 3D thermo-radiative models, such as DART [20], TUF-3D [21], LASER/F [22], SOLENE-Microclimat [23], ENVI-met [24], etc., which simulate the energy transfers at the soil-atmosphere interface for urban environment. Those models are applied and evaluated in several studies [25-30]. However, most of those models provide broadband estimations, which are then difficult to convert to narrowband estimations corresponding to the ASTER spectral bands. For those allowing narrowband simulations, they require complex parameterization datasets. Setting out from these facts, this study proposes a method to estimate the total downwelling TIR radiation narrowband based on the geometric characteristics of the surface derived from a digital surface model (DSM) combined with metric spatial resolution LST simulated with a simple 3D radiative model parameterization. This hybrid approach has the advantage to overcome the spectral dimension problem by using the LST, which can be simulated using rather simple parameterization as compared to spectral radiances, while still accounting for the pixel non-isothermal behavior. Once validated, the total downwelling TIR radiation can be provided as input to the TES to produce LSE and LST maps corrected for the impact of surface geometry. Those maps can then be compared to equivalent non-corrected maps and to the ASTER Global Emissivity Dataset v3. The results of the study are divided into two parts:

- Validation of the estimation of the total downwelling TIR radiation based on the geometric characteristics of the surface and the 3D model simulations.

- $\quad$ Production of effective LSE and LST maps using the TES accounting for the surface geometry and comparison with equivalent maps computed with the original method. 
The method developed to estimate the total downwelling TIR radiation is described in Section 2, the study area is presented in Section 3, while the data and the 3D thermo-radiative models used in this study are detailed in Section 4. Then, Section 5 provides results concerning the validation of the estimated total downwelling TIR radiation along with the comparison of three LSE and LST maps derived from an ASTER image produced with and without geometric correction. Finally, Section 6 presents the discussion and conclusions.

\section{Method}

The TES algorithm simultaneously retrieves the LSE and LST from multispectral TIR satellite data based on the relation between surface-leaving radiance measured by the sensor (compensated for atmospheric absorption and path radiance) and the downwelling TIR radiation received by the surface [16]. The ASTER emissivity product provided by the NASA's Jet Propulsion Laboratory is derived from the surface-leaving radiance $\left(\mathrm{W} \cdot \mathrm{m}^{-2} \cdot \mathrm{sr}^{-1} \cdot \mu \mathrm{m}^{-1}\right)$ and the downwelling sky irradiance $\left(\mathrm{W} \cdot \mathrm{m}^{-2} \cdot \mu \mathrm{m}^{-1}\right)$ for the five ASTER TIR bands at $90 \mathrm{~m}$ of spatial resolution from the AST09 product [31]. The downwelling sky irradiance from AST09 is simulated using MODTRAN and corresponds to the amount of TIR radiation received at the top of the urban canopy. In urban areas, the total downwelling TIR radiation received for a given pixel is not equal to the top-of-canopy downwelling TIR radiation due to the roughness of the surface. As shown in Figure 1, several TIR radiative intra-pixel processes contribute to the total downwelling TIR radiation: (1) radiation coming from the atmosphere $\left(R_{a t}^{\downarrow}\right)$; (2) radiation coming from the scene, divided in two components: the emission $\left(R_{e m}^{\downarrow}\right)$ and multiple reflections $\left(R_{m r}^{\downarrow}\right)$ from the surrounding elements.

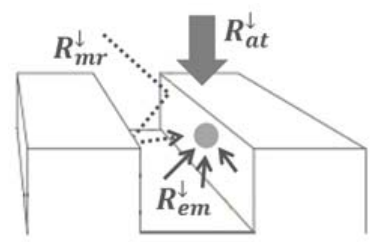

Figure 1. Scheme of the different radiative fluxes contributing to the total downwelling TIR radiation: atmospheric radiation (thick arrow), scene radiations divided between emission (thin arrow) and multiple reflections (dash arrow).

To integrate the impact of the surface geometry into the TES, the idea is to estimate and use the total downwelling TIR radiation $\left(R_{T, \lambda}^{\downarrow}\right)$ by pixel for each ASTER spectral band instead of the downwelling sky irradiance $\left(\mathrm{W} \cdot \mathrm{m}^{-2} \cdot \mu \mathrm{m}^{-1}\right)$ from the AST09 product (Figure 2). At pixel scale, the total downwelling TIR radiation should take into account the three incident contributions as follow:

$$
R_{T, \lambda}^{\downarrow}=R_{a t, \lambda}^{\downarrow}+R_{e m, \lambda}^{\downarrow}+R_{m r, \lambda}^{\downarrow}
$$

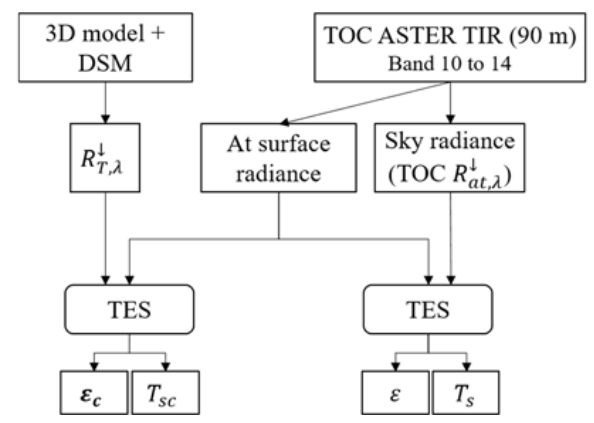

Figure 2. Processing steps to estimate corrected and non-corrected land surface temperature $\left(T_{S}\right)$ and emissivity $(\varepsilon)$ from ASTER data (TOC = top of canopy, DSM = digital surface model). 
This paper proposes a method to derive $R_{T, \lambda}^{\downarrow}$ for the 5 ASTER TIR bands based on the geometric characteristics of the considered scene and simulated LST.

\subsection{Atmospheric TIR Radiation}

When considering a given location $x$ in an urban canyon (e.g., the grey dot in Figure 1), the downwelling TIR radiation coming from the atmosphere in a given band $\left(R_{a t, \lambda, x}^{\downarrow}\right)$ is derived from the downwelling sky radiation at the top of the urban canopy in that band $\left(R_{a t, \lambda, H}^{\downarrow}\right)$ weighted by the portion of sky visible from that location, namely its sky view factor $(S V F)$, and is expressed as:

$$
R_{a t, \lambda, x}^{\downarrow}=S V F \cdot R_{a t, \lambda, H}^{\downarrow}
$$

To estimate $R_{a t, \lambda}^{\downarrow}$ at pixel level, the $S V F$ should be representative of the considered pixel. Groleau et al. and Bernabé et al. [32,33] showed that the effective $S V F\left(S V F_{T}\right)$ for a given urban area varies linearly with facade density $\left(D_{F}\right)$ and established the following relationship:

$$
S V F_{T}=1-D_{F}
$$

with:

$$
D_{F}=S_{F} / S_{T}
$$

$S_{T}$ being the total land surface within the considered area, in this case a pixel. It corresponds to the sum of the total surface of roof elements $\left(S_{R}\right)$, the total surface of facade elements $\left(S_{F}\right)$ and the total surface of ground $\left(S_{G}\right)$.

Then, the atmospheric contribution is estimated at pixel scale for a given ASTER band as:

$$
R_{a t, \lambda}^{\downarrow}=S V F_{T} \cdot R_{a t, \lambda, H}^{\downarrow}
$$

\subsection{Scene Emitted Radiation}

The contribution of the scene emission to the energy travelling below the rooftops at location $x$ $\left(R_{e m, \lambda, x}^{\downarrow}\right)$ is computed by weighting the scene emitted TIR radiation $\left(R_{e m, \lambda, s}\right)$ by the terrain view factor, the portion of scene elements visible from location $x$. In this study, the terrain view factor is estimated as $(1-S V F)$. Furthermore, considering only the radiative exchanges below the rooftops, roofs emitted radiation is assumed as negligible as most of it is sent back to the atmosphere and very few contributes to the amount of TIR radiations remaining within the canopy. Thus, only the emission from the facades and the ground are considered. The contribution coming from the scene emission is then equal to:

$$
R_{e m, \lambda, x}^{\downarrow}=(1-S V F) R_{e m, \lambda, s}^{\downarrow}
$$

Using $S V F_{T}$ (Equation (3)), the scene emitted TIR radiation contribution for a given pixel is estimated as:

$$
R_{e m, \lambda}^{\downarrow}=\left(1-S V F_{T}\right) R_{e m, \lambda, s}^{\downarrow}
$$

$R_{e m, \lambda, s}^{\downarrow}$, the TIR radiation emitted by all facade and ground surfaces comprised in a pixel, is derived from the LST simulated by the 3D thermo-radiative model. The latter provides LST values for each mesh of a 3D scene fragmented at metric resolution. Then, for each mesh $i$, the emitted TIR radiation $R_{e m, \lambda, i}^{\downarrow}$ is computed from the simulated LST and the spectral emissivity set for each element of the scene, respectively $R_{T s, i}^{\downarrow}$ and $\varepsilon_{\lambda, i}$, as follow:

$$
R_{e m, \lambda, i}^{\downarrow}=\varepsilon_{\lambda, i} R_{T s, i}^{\downarrow}
$$


Then, $R_{e m, \lambda, s}^{\downarrow}$ is computed as the surface weighted average of $R_{e m, \lambda, i}^{\downarrow}$ emitted by each facade and ground meshes within the pixel, $S_{i}$ being the surface the meshes:

$$
R_{e m, \lambda, S}^{\downarrow}=\frac{\sum R_{e m, \lambda, i}^{\downarrow} S_{i}}{\sum S_{i}}
$$

\subsection{Multiple Reflections}

The amount of TIR radiation received at location $x$ from the multiple reflections $\left(R_{m r, \lambda, x}^{\downarrow}\right)$ is estimated based on the capacity of the scene to reflect the TIR radiation coming from the atmosphere and the scene emission. The reflectivity of the scene is expressed as $\left(1-\varepsilon_{s, \lambda}\right)$ and the portion of reflected TIR radiation remaining in the urban canopy is estimated based on the terrain view factor as follow:

$$
R_{r, \lambda, 1, x}^{\downarrow}=(1-S V F)\left(1-\varepsilon_{s, \lambda}\right)\left[S V F R_{a t, \lambda, H}^{\downarrow}+(1-S V F) R_{e m, \lambda, T}^{\downarrow}\right]
$$

As for the emitted scene radiation, the emission from the roofs is neglected as we only consider the radiation trapped into the urban canopy. Then, the first iteration to estimate the amount of reflected radiation for a given pixel is computed as follow:

$$
R_{r, \lambda, 1}^{\downarrow}=\left(1-S V F_{T}\right)\left(1-\varepsilon_{s, \lambda}\right)\left[S V F_{T} R_{a t, \lambda, H}^{\downarrow}+\left(1-S V F_{T}\right) R_{e m, \lambda, s}^{\downarrow}\right]
$$

Using $R_{i, \lambda, s}^{\downarrow}=\left(S V F_{T} R_{a t, \lambda, H}^{\downarrow}+\left(1-S V F_{T}\right) R_{e m, \lambda, s}^{\downarrow}\right)$, and after the several reflections:

$$
\begin{aligned}
& R_{r, \lambda, 2}^{\downarrow}=\left(1-S V F_{T}\right)^{2}\left(1-\varepsilon_{s, \lambda}\right)^{2} R_{i, \lambda, s}^{\downarrow} \\
& R_{r, \lambda, n}^{\downarrow}=\left(1-S V F_{T}\right)^{n}\left(1-\varepsilon_{s, \lambda}\right)^{n} R_{i, \lambda, s}^{\downarrow}
\end{aligned}
$$

Then, the total amount of reflected TIR radiation remaining in the urban canopy can be written as:

$$
\begin{gathered}
R_{m r, \lambda}^{\downarrow}=R_{r, \lambda, 1}^{\downarrow}+a R_{r, \lambda, 1}^{\downarrow}+\ldots+a^{n-1} R_{r, \lambda, 1}^{\downarrow} \\
R_{m r, \lambda}^{\downarrow}=\frac{R_{r, \lambda, 1}^{\downarrow}\left(1-a^{n-1}\right)}{(1-a)}
\end{gathered}
$$

With $a=\left(1-S V F_{T}\right)\left(1-\varepsilon_{s, \lambda}\right)$.

When $\mathrm{n}$ tends to infinity, $a^{n-1}$ tends to 0 , then:

$$
\begin{gathered}
R_{m r, \lambda}^{\downarrow}=\frac{R_{r, \lambda, 1}^{\downarrow}}{\left[1-\left(1-S V F_{T}\right)\left(1-\varepsilon_{s, \lambda}\right)\right]} \\
R_{m r, \lambda}^{\downarrow}=\frac{\left(1-S V F_{T}\right)\left(1-\varepsilon_{s, \lambda}\right)\left[S V F_{T} R_{a t, \lambda, H}^{\downarrow}+\left(1-S V F_{T}\right) R_{e m, \lambda, s}^{\downarrow}\right]}{\left[1-\left(1-S V F_{T}\right)\left(1-\varepsilon_{s, \lambda}\right)\right]}
\end{gathered}
$$

\section{Study Area}

The method is developed and tested over the urban area of Strasbourg. Located in the east of France, this agglomeration covers $78.26 \mathrm{~km}^{2}$ and counts slightly more than 276,000 inhabitants. The effective LSE and the LST are estimated for three districts presenting different urban configurations, the objective being to investigate the impact of the geometric correction and to quantify the errors caused by neglecting the surface geometry. The three districts, namely the historical center, the university district and the Neudorf district, are presented in Figure 3 and their morphological characteristics are summarized in Table 1. 
Table 1. Morphological characteristics of each district.

\begin{tabular}{cccc}
\hline & Historical Center & University District & Neudorf District \\
\hline Average building height $(\mathrm{m})$ & 19.5 & 19.7 & 13.6 \\
Building density & 0.54 & 0.28 & 0.70 \\
\hline
\end{tabular}

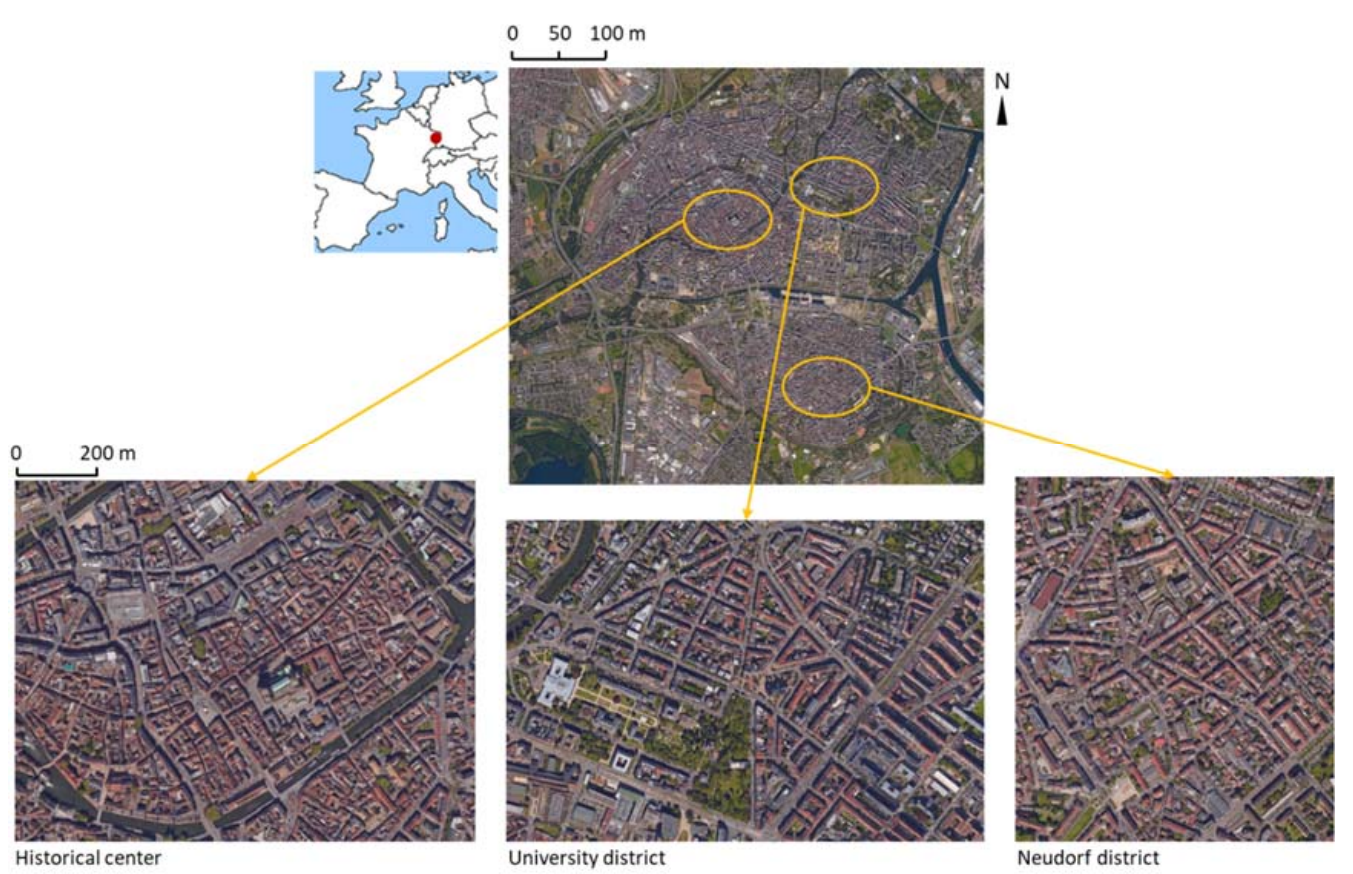

Figure 3. Strasbourg urban area (top) and the three districts used for land surface emissivity and temperature estimation (bottom).

\section{Data and 3D Thermo-Radiative Models}

\subsection{D Surface Geometry}

The 3D geometric information used to compute the morphological characteristics of the surface by pixel is derived from the IGN (French National Institute for Geographical Information) dataset BD Topo (Figure 4) [34]. The BD Topo is a simplified 3D vectorial description of the objects composing the surface with a metric resolution and scales ranging from 1:5000 to 1:50,000. This dataset covers all the geographical and administrative entities of France. It is used to derive the facade density within each pixel required for the computation of the effective SVF as well as the digital surface model (DSM) used by the $3 \mathrm{D}$ thermo-radiative models.

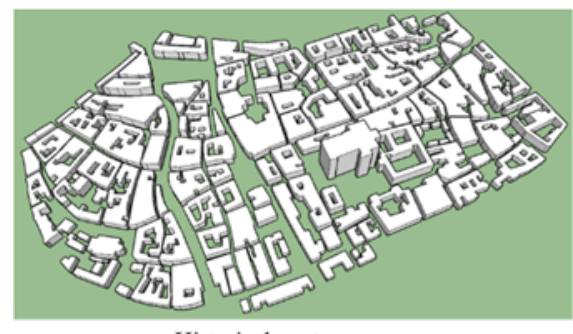

Historical center

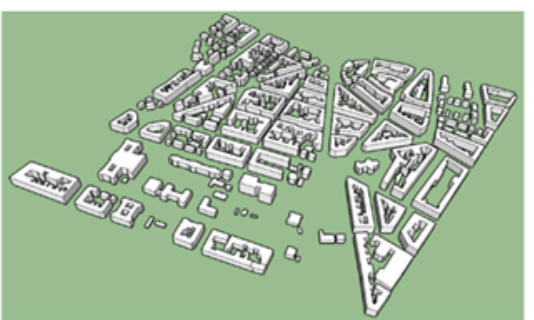

University district

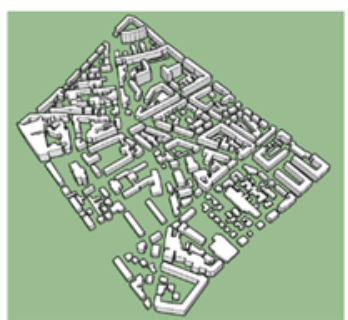

Neudorf district

Figure 4. 3D datasets of the three districts derived from the BD Topo (IGN). 


\subsection{ASTER Products}

The ASTER products used in this study are distributed at the NASA Land Processes Distributed Active Archive Center (LP DAAC) at the U.S. Geological Survey (USGS) Earth Resources Observation and Science (EROS).

\subsubsection{TES Inputs}

The TES inputs consist in the surface-leaving radiance measured in the 5 TIR bands of ASTER and the corresponding downwelling sky irradiance for each band. In this study, the TIR at surface-leaving radiance provided by the AST09 product (bands 10 to 14) is used. This product was derived from an ASTER image acquired on the 28 May 2013 and also provide the sky irradiance at the top of the urban canopy, which will be used to compare to the proposed method. The validation of those products showed that, under ideal conditions and for a large homogeneous scene, the temperature and emissivity standard products are predicted to be within $+1.5 \mathrm{~K}$ and +0.015 of correct values, respectively [17].

\subsubsection{ASTER Global Emissivity Dataset}

The ASTER GEDv3 propose an average emissivity at global scale computed using all ASTER scenes from 2000 to 2008 . The product is available at $100 \mathrm{~m}, 1 \mathrm{~km}$ and $5 \mathrm{~km}$ spatial resolution. The emissivity was retrieved using the TES algorithm combined with a water vapor scaling (WVS) atmospheric correction approach [35]. The validation of the product shows an agreement to within $1.5 \%$ [36]. In this study, the dataset at $100 \mathrm{~m}$ is used to compare with the LSE maps retrieved after applying the proposed geometric correction.

\subsection{D Thermo-Radiative Models}

To consider the non-isothermal behavior of the pixel, the LST used to estimate the TIR radiation emitted by the scene is simulated at mesh level using a 3D thermo-radiative model. In this study, two models are used: LASER/F [22] and SOLENE-Microclimate [23]. Both models simulate 3D radiative and energy balance for each mesh of a discretized urban area based on thermodynamics principles. Those models have been validated and used in several studies [29,30,37,38]. As compared to other models based on the street canyon assumption [39-41], the distribution of the radiative energy is performed integrating the complexity and variety of the 3D geometric configurations. The urban canopy is reproduced using 3D shapes of all the objects constituting the urban environment, as provided by the DSM; considering their geometrical and thermophysical properties. Here, the DSM is derived from the BD Topo. Only buildings are considered-no vegetation is included in the 3D surface model. Prior to the computations, the scene is fragmented in small elementary meshes. The simulations are performed for each mesh, providing results at a resolution of a few square meters. The granularity of the simulation depends of the fragmentation size, the latter influencing the computation time as well. LASER/F is used to quantify the impact of the surface geometry on the estimation of downwelling TIR radiation and to validate the correction method, both at canyon level. To extend the application of the method to the district level, simulations are performed using SOLENE-Microclimate, whose implementation allows to compute significantly larger 3D scenes as compared to LASER/F.

Both models require ground meteorological forcing data, such as air humidity and temperature, incoming radiative fluxes (top of canopy short and longwave radiations), precipitation, wind speed and orientation. These data are acquired on a regular basis in Strasbourg by fixed meteorological stations located in the city center [42].

\section{Results}

This section is divided in two parts. In the first part, the method proposed to estimate the total downwelling TIR radiation is validated at canyon level based on LASER/F simulations. In the second 
part, the total downwelling TIR radiation is estimated at district scale with the validated method and SOLENE-microclimat and used in the TES to derive LSE and LST maps from an ASTER image. Those maps are compared to equivalent maps produced using TOC-downwelling TIR radiation to evaluate the differences in LSE and LST obtained with the TES with and without geometric correction and to the ASTER Global Emissivity Dataset v3.

\subsection{Validation of $R_{T}^{\downarrow}$ at Canyon Scale}

The validation presented in this section compares the total, atmospheric and scene downwelling TIR radiations estimated using the proposed method (hereafter mentioned as 'estimated') to the corresponding fine-grained simulated values, computed broadband by the reference 3D model LASER/F (hereafter mentioned as 'reference'). First, the validation is performed for 27 different canyon configurations with three different building heights $(10,30,50 \mathrm{~m})$ and street width $(5,25$, $50 \mathrm{~m})$ representative of Strasbourg urban area and three different orientations $\left(0,45,90^{\circ}\right)($ Figure 5). Four periods of 3 to 6 clear days taken in March, June, September and December are extracted from a set of meteorological data measured at the ground to force the model. For the fragmentation, the mesh minimum size is set to $15 \mathrm{~m}^{2}$. The albedo, emissivity, and thermal properties of the materials of the scene are detailed in Table 2. Those settings are defined according to the outputs of several experiments carried out with the model over Strasbourg over the past decade [38,43]. In this case, the emissivity is kept constant for all surfaces of the scene, which is not the case in reality. However, this assumption is acceptable as a sensitivity analyses performed with LASER/F showed that varying the emissivity values from 0.85 to 0.95 lead to variations in surface temperature lower than $0.24{ }^{\circ} \mathrm{C}$ [38]. The reference values are simulated for each mesh of the scene and then averaged at canyon level. The overall computation time for each period and each configuration considering the described scenes is provided in Appendix A to this paper (Table A1).

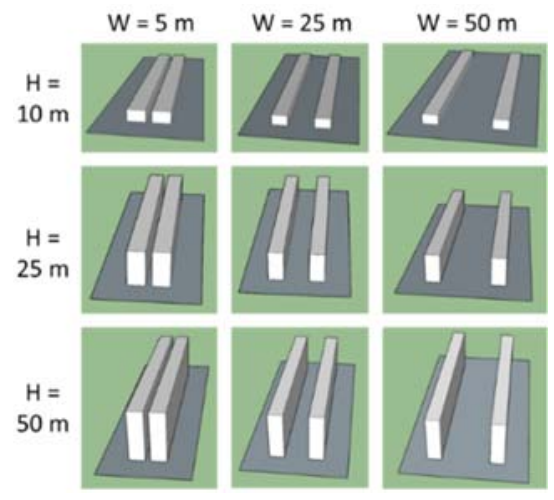

Figure 5. The different canyon configurations used to set and validate $R_{T}^{\downarrow}$ estimation.

Table 2. Materials properties used for each canyon configuration (specific heat $\left(\mathrm{c}, \mathrm{J} \cdot \mathrm{kg}^{-1} \cdot \mathrm{K}^{-1}\right)$, thermal conductivity $\left(\mathrm{k}, \mathrm{W} \cdot \mathrm{m}^{-1} \cdot \mathrm{K}^{-1}\right)$, density $\left(\rho, \mathrm{kg} \cdot \mathrm{m}^{-3}\right)$ ).

\begin{tabular}{cccc}
\hline & Wall & Roof & Ground \\
\hline Albedo & $\mathbf{0 . 3}$ & $\mathbf{0 . 1 5}$ & $\mathbf{0 . 1 0 5}$ \\
\hline Emissivity & $\mathbf{0 . 9 5}$ & $\mathbf{0 . 9 5}$ & $\mathbf{0 . 9 5}$ \\
\hline & $0.05 \mathrm{~m}$ roughcast & $0.06 \mathrm{~m}$ red tiles & $0.06 \mathrm{~m}$ asphalt \\
Layer composition & $(1000,1.5,1900)$ & $(1000,0.8,1634)$ & $(1021,1.16,2400)$ \\
$\left(\mathrm{c}\left(\mathrm{J} \cdot \mathrm{kg}^{-1} \cdot \mathrm{K}^{-1}\right), \mathrm{k}\left(\mathrm{W} \cdot \mathrm{m}^{-1} \cdot \mathrm{K}^{-1}\right), \rho\left(\mathrm{kg} \cdot \mathrm{m}^{-3}\right)\right)$ & $0.24 \mathrm{~m}$ concrete & $0.15 \mathrm{~m}$ isolating material & $1 \mathrm{~m}$ bedrock \\
& $(1000,1.88,2000)$ & $(1450,0.04,20)$ & $(2100,1,1000)$ \\
& $0.04 \mathrm{~m}$ plaster & & \\
& $(1000,0.35,900)$ & & \\
\hline
\end{tabular}


Figure 6 presents a set of nine validation graphs for canyon configurations with different building and street dimensions but the same orientation. The latter was found to have no significant impact on the results. The validation of $R_{T}^{\downarrow}$ is divided into atmospheric and scene contributions, the latter comprising the scene emitted radiation and the multiple reflections. Each graph shows $R_{T}^{\downarrow}$ represented with black circles, $R_{a t}^{\downarrow}$ with dark grey dots and $R_{s}^{\downarrow}$ with light grey dots along with the RMSE computed for $R_{T}^{\downarrow}$ only. A detailed validation of atmospheric and scene contributions is provided further. Figure 6 highlights that very accurate values of $R_{T}^{\downarrow}$ can be retrieved using the proposed method based on the geometry characteristics of the canyon. The largest RMSE values $\left(1.8,2.1\right.$ and $\left.2.2 \mathrm{~W} \cdot \mathrm{m}^{-2}\right)$ occur for canyons at 50-m streetwide, no matter what the height of the buildings. Both $R_{a t}^{\downarrow}$ and $R_{s}^{\downarrow}$ are also correctly estimated, even if a slight overestimation of the scene contribution and underestimation of the atmospheric contribution can be observed for the canyons with buildings higher than $30 \mathrm{~m}$ and streets wider than $25 \mathrm{~m}$. This figure shows that the atmospheric contribution decreases when street width decreases and when building height increases. With building height below $30 \mathrm{~m}$, the atmospheric radiation represents the major contribution to the total downwelling TIR radiation. On the contrary, the scene contribution increases together with building height and decreases when street width increases. Nevertheless, both contributions seem to be more influenced by the height of the building than the street width. The same behavior was observed for the four time periods.

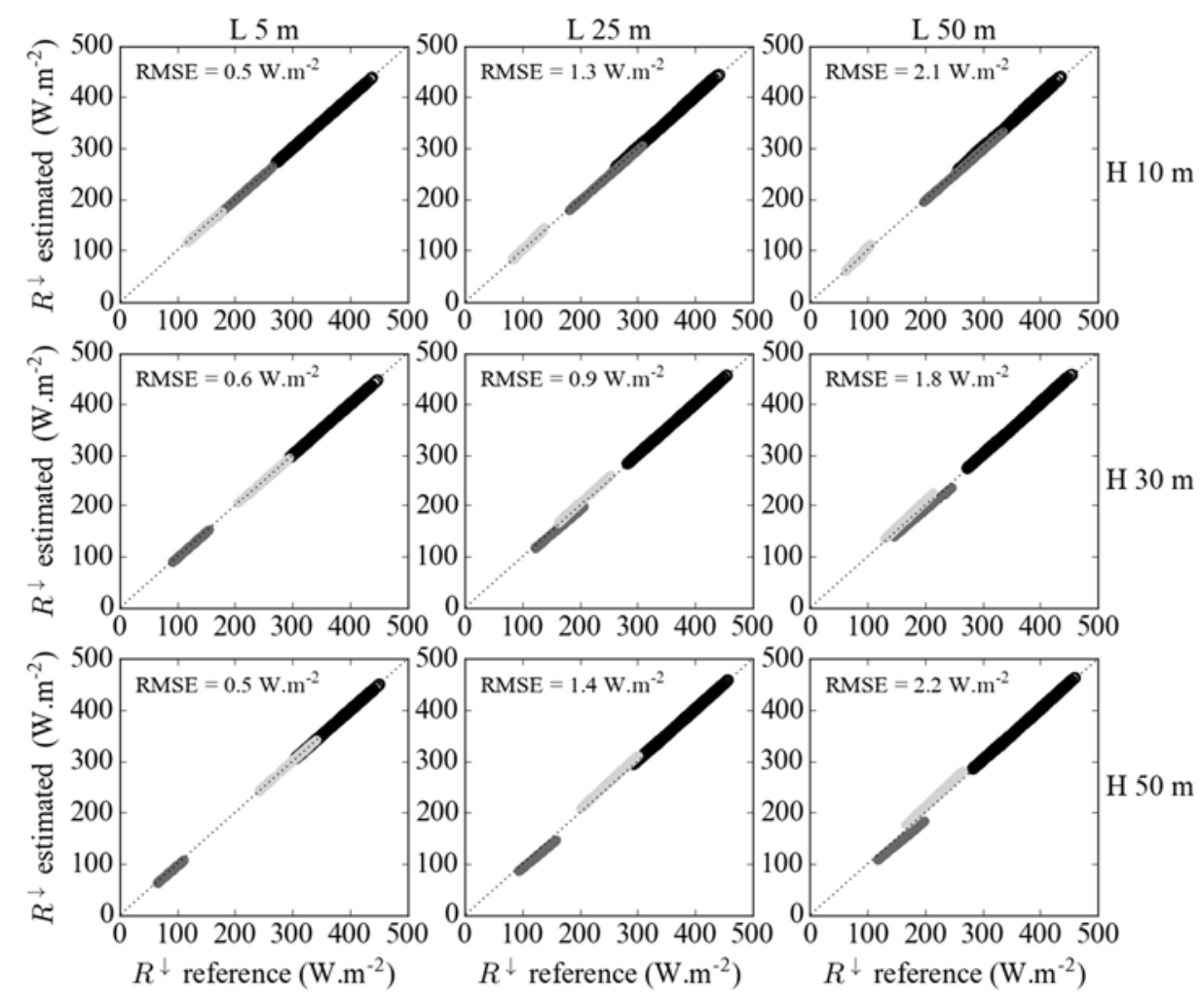

Figure 6. Comparison of estimated and reference total (black circles), atmospheric (dark grey dots) and scene (light grey dots) downwelling TIR radiation for nine canyon configurations (orientation $0^{\circ}$ ). The Root Mean Square Error (RMSE) is provided for the estimation of the total downwelling TIR radiation.

Based on the different canyon configurations and the four time periods spread over the year, the impact of the geometry on the total downwelling TIR radiation is quantified. Figure 7 shows the difference between the non-corrected downwelling TIR radiation at the top of the canopy (TOC) and the computed $R_{T}^{\downarrow}$ integrating the impact of the surface geometry for each time period and configuration. Differences up to $68 \mathrm{~W} \cdot \mathrm{m}^{-2}$ ( $25 \%$ of the TOC value) are reached after correcting for the geometry. 
Thus, neglecting the impact of geometry could lead to errors of about 0.05 concerning the surface emissivity and $4{ }^{\circ} \mathrm{C}$ for the surface temperature. If expressed as the percentage of TOC-downwelling TIR radiation, the largest differences are obtained in March and December, when the amount of TOC-downwelling TIR radiation is the lowest. For those periods with lower atmospheric contribution, accounting for the scene contribution has a large impact on the total downwelling TIR radiation. In all cases, the largest differences are observed for canyons with tall buildings and narrow streets. As previously, those differences appear to be more linked to the building height than to the street width. No significant correlation between the height/width ratio of the canyons and those differences could be highlighted.
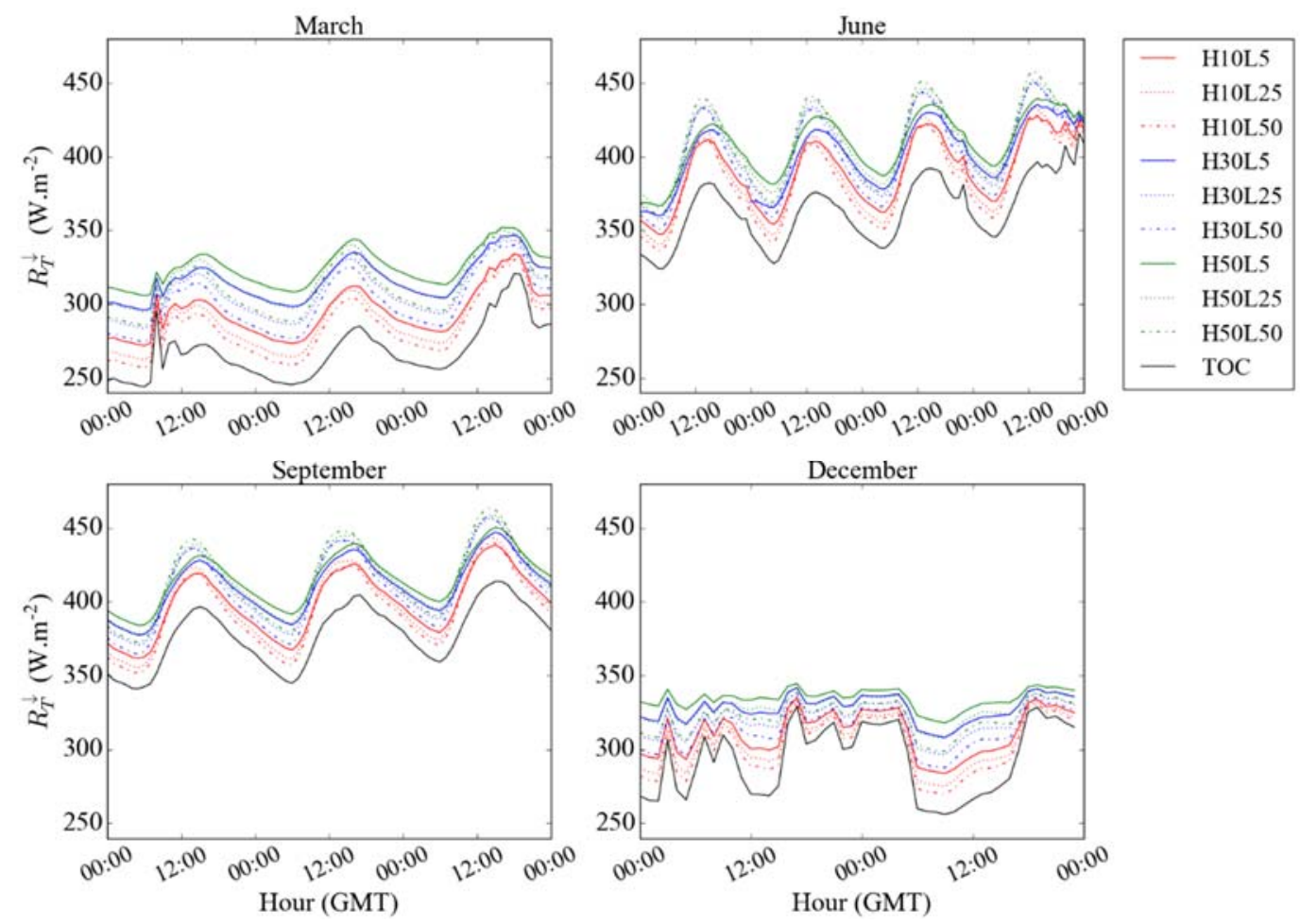

Figure 7. Top-of-canopy (TOC) downwelling TIR radiation and total downwelling TIR radiation for nine canyon configurations (orientation $\left.0^{\circ}\right)$ for the four time periods $(\mathrm{H}=$ building height $(\mathrm{m})$, $\mathrm{L}=$ street length $(\mathrm{m})$ ).

\subsubsection{Atmospheric TIR Radiation $\left(R_{a t}^{\downarrow}\right)$}

Based on the validation presented in Figure 6, the RMSE of the estimation of $R_{a t}^{\downarrow}$ is provided in Table 3. The largest RMSE $\left(11.6 \mathrm{~W} \cdot \mathrm{m}^{-2}\right)$ is observed for the configuration with the largest street and the highest building.

Table 3. RMSE of the estimation of $R_{a t}^{\downarrow}$ expressed in $\mathrm{W} \cdot \mathrm{m}^{-2}$.

\begin{tabular}{cccc}
\hline RMSE $\left(\mathbf{W} \cdot \mathbf{m}^{-\mathbf{2}}\right)$ & L: $\mathbf{5} \mathbf{~ m}$ & L: $\mathbf{2 5} \mathbf{~ m}$ & L: $\mathbf{5 0} \mathbf{~ m}$ \\
\hline H: $10 \mathrm{~m}$ & 0.7 & 2.4 & 1.9 \\
H: $30 \mathrm{~m}$ & 1.5 & 6.2 & 7.1 \\
H: $50 \mathrm{~m}$ & 2.3 & 8.8 & 11.6 \\
\hline
\end{tabular}

The main parameter required to estimate the contribution of the atmosphere is the effective SVF $\left(S V F_{T}\right)$ for a given canyon. Errors in $R_{a t}^{\downarrow}$ estimation are directly linked to the estimation of $S V F_{T}$. In this method, $S V F_{T}$ is derived from the surface geometry based on its direct relation with the facade density 
as expressed in Equation (3). The validation of the SVF estimated from the facade density $\left(S V F_{T}\right)$ according to $[32,33]$ using the SVF computed by LASER/F as reference, provides very accurate results $(\mathrm{RMSE}=0.017)$, and shows that the proposed method is relevant to estimate $S V F_{T}$ for a given canyon. Further analysis pointed out that, when both building height and street width increase, the $S V F_{T}$ tends to be underestimated. This explains the slight underestimation of the atmospheric contribution observed in Figure 6 for canyons with buildings higher than $30 \mathrm{~m}$ and streets wider than $25 \mathrm{~m}$.

\subsubsection{Scene-Emitted Radiation and Multiple Reflections}

Based on the validation presented in Figure 6, the RMSE of the estimation of $R_{S}^{\downarrow}$ is provided in Table 4. As for the atmospheric contribution, the largest RMSE $\left(13.6 \mathrm{~W} \cdot \mathrm{m}^{-2}\right)$ is observed for the configurations with building height above $30 \mathrm{~m}$ and street width larger than $25 \mathrm{~m}$.

Table 4. RMSE of the estimation of $R_{S}^{\downarrow}$ expressed in $\mathrm{W} \cdot \mathrm{m}^{-2}$.

\begin{tabular}{cccc}
\hline RMSE $\left(\mathbf{W} \cdot \mathbf{m}^{-\mathbf{2}}\right)$ & L: $\mathbf{5} \mathbf{~ m}$ & L: $\mathbf{2 5} \mathbf{~ m}$ & L: $\mathbf{5 0} \mathbf{~ m}$ \\
\hline H: $10 \mathrm{~m}$ & 0.3 & 3.3 & 3.5 \\
H: $30 \mathrm{~m}$ & 1.1 & 7.1 & 8.5 \\
H: $50 \mathrm{~m}$ & 2.0 & 10.1 & 13.6 \\
\hline
\end{tabular}

As for the atmospheric contribution, the accuracy of the scene contribution estimation is directly linked to the $S V F_{T}$. However, it also depends on the LST of the different elements of the canyon and the assumptions made to estimate the emitted radiation. This LST is estimated at mesh level using the $3 \mathrm{D}$ thermo-radiative model LASER/F in order to consider the non-isothermal behavior of the pixel. Very large temperature differences can be observed in an urban canyon, especially around solar noon. A sensitivity analysis is carried out to quantify the impact of a variation of the LST on the final $R_{T}^{\downarrow}$ estimation. To do so, $R_{T}^{\downarrow}$ is estimated using the LST simulated by the model increased or decreased by 1,2 or $5{ }^{\circ} \mathrm{C}$. The differences are computed as percentage of the value derive from the original LST as shown in Figure 8.

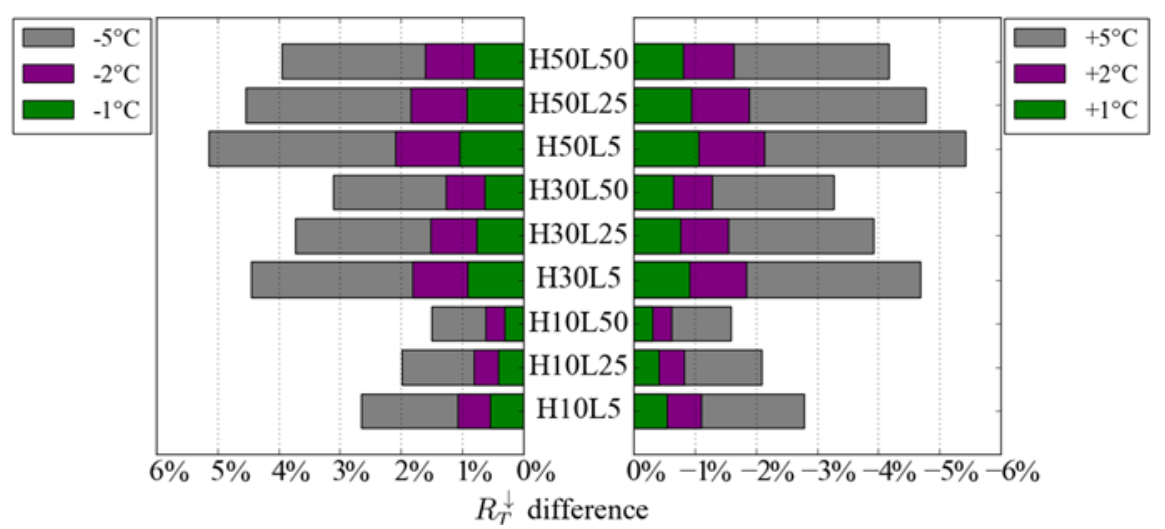

Figure 8. Differences in $R_{T}^{\downarrow}$ with LST varying from -5 to $+5{ }^{\circ} \mathrm{C}$ around the reference LST value, expressed as percentage of reference value.

The results presented in Figure 8 highlight the fact that it is very important to have realistic surface temperature for the considered scene or pixel, since a variation of $5{ }^{\circ} \mathrm{C}$ already leads to an error larger than $5 \%$ of the reference value. In a canyon, during the daytime, temperature differences up to several tens of degrees can be observed between lighted and shadowed areas. Furthermore, if well parameterized, the thermo-radiative models such as Laser/F simulate LST with an accuracy of about $2{ }^{\circ} \mathrm{C}$ [38], thus using models outputs would not introduce more than $2 \%$ of error in the final estimation. 
To illustrate the necessity to consider a pixel as non-isothermal, Figure 9 shows the variability of the amount of radiation emitted by the scene according to the LST value used to estimate it (Equation [9]). The dots represent $R_{e m}^{\downarrow}$ estimated according to the proposed method and the error areas are estimated taking the minimum and maximum LST values observed over the scene for each canyon configuration for each time step. The figure presents hourly estimates for four clear days selected in March (blue), June (green), September (red) and December (yellow). The largest errors areas are observed in June and September, when the range of LST values observed over each scene is the wider. In most of the cases, the isothermal assumption would lead to an overestimation of the contribution of the scene (maximum $+196 \mathrm{~W} \cdot \mathrm{m}^{-2}$ ), except for canyon with low buildings and large streets.

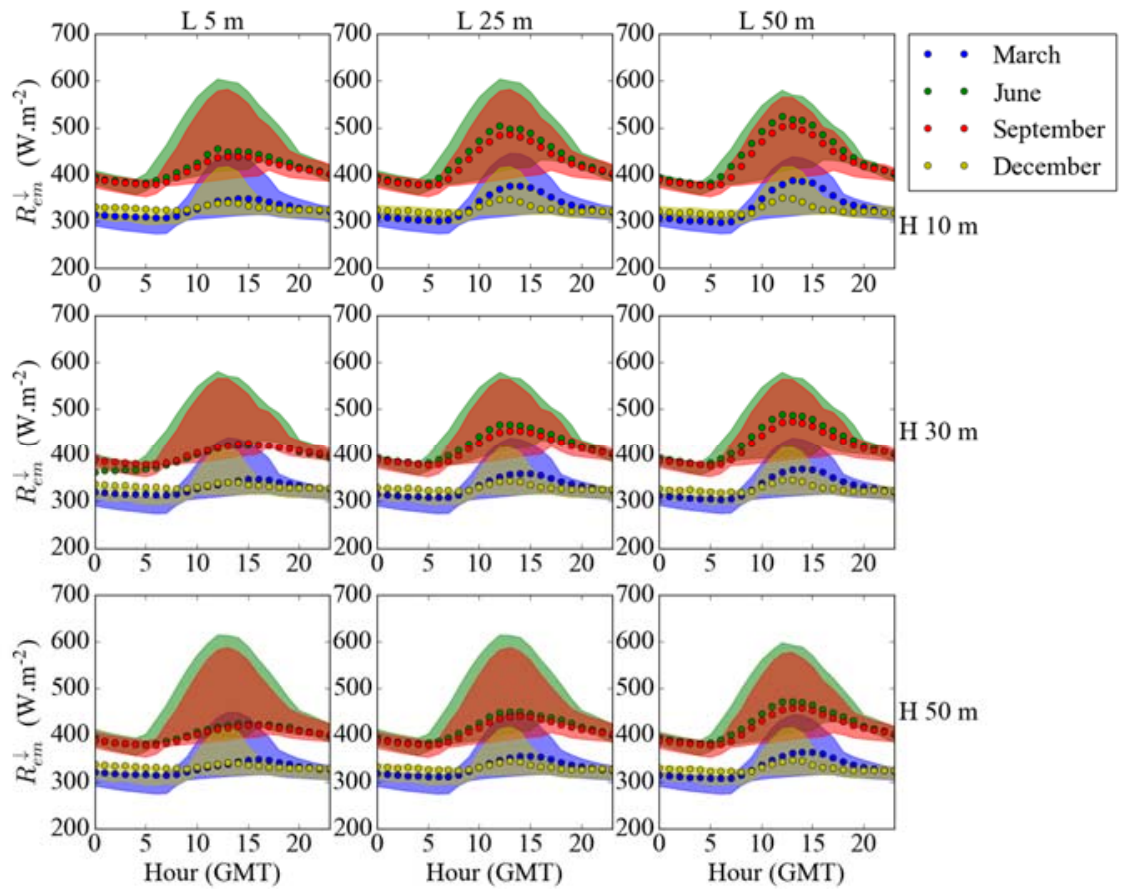

Figure 9. Hourly estimates of $R_{e m}^{\downarrow}$ for four clear days: one in March (blue), one in June (green), one in September (red) and one in December (yellow) and for the nine canyon configurations. The dots represent $R_{e m}^{\downarrow}$ estimated using the proposed method and the error areas are computed using the minimum and maximum LST values observed over the scene.

A second test compares two different values of hourly emitted scene radiation for each time step, both estimated using Equation (9), but based on two different model simulations. The first value comes from a simulation using the 3D geometry derived from the BD Topo, while the second value is simulated using the same thermodynamic characteristics but over a flat surface. For the latter, the same proportion of street, building and roof materials are kept, only the geometry is removed. The distributions of the differences observed between the two values are presented in Figure 10. As for Figure 9, the results by months (Figure 10a) confirm that larger errors are observed in June and September, when the LST range over the scene is the wider. In Figure 10b, the results also show larger discrepancies for the configuration with tall buildings and narrow streets. It also shows that considering the surface as flat would mostly lead to an overestimation of the contribution of the scene, except for canyon with low buildings and large streets. 
(a)

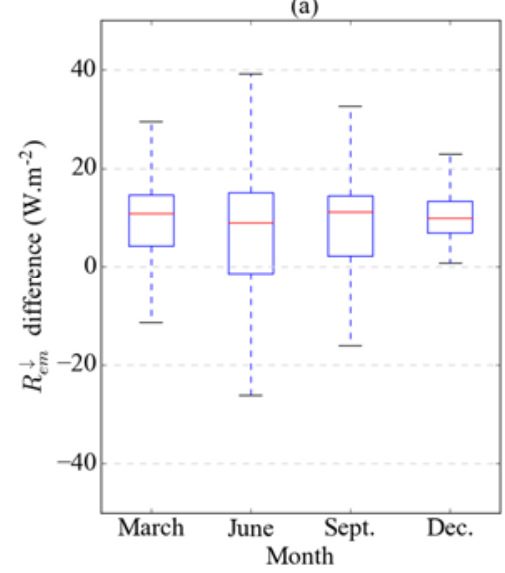

(b)

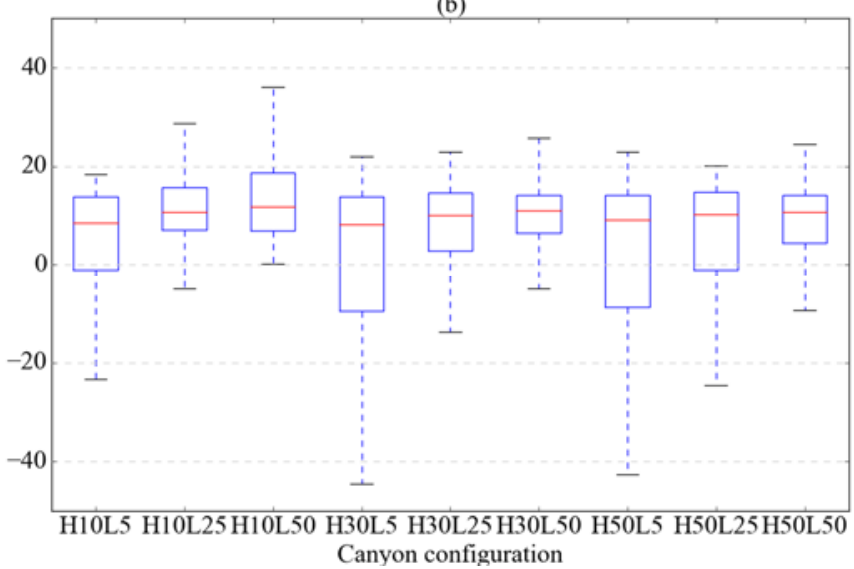

Figure 10. Distribution of the differences between hourly scene emitted radiation estimated integrating the 3D geometry and assuming a flat surface, by month (a) and by canyon configuration (b). The red line being the median value, the upper and lower limits of the box the upper and lower quartile respectively and the whiskers representing the minimum and maximum values.

\subsubsection{Validation Over a District}

After validating the proposed method to derive $R_{T}^{\downarrow}$ integrating all the contributions over different canyon configurations, the method is applied and tested over a larger and more complex scene. This case deals with a real scene, extracted from the BD Topo covering the Strasbourg urban area (Figure 11). The average building height of the scene is $21.5 \mathrm{~m}$ and the average street width is $13.5 \mathrm{~m}$.
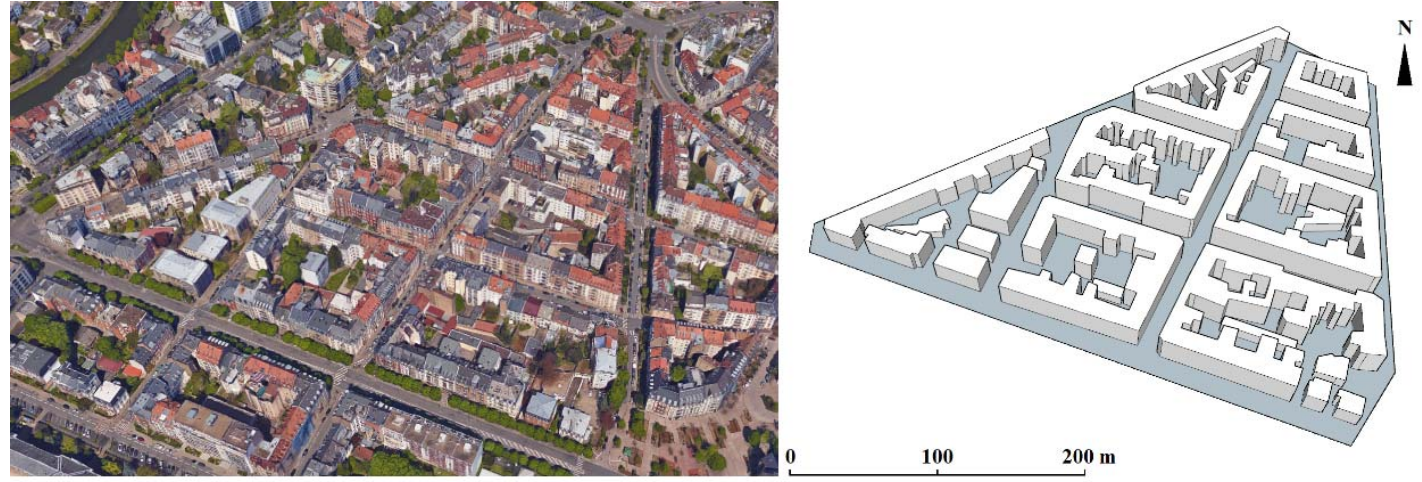

Figure 11. Google maps image and 3D geometry of the scene extracted from the BD Topo to extend the validation tests.

As for the canyons, the estimation of over the entire scene is validated. The value computed by the 3D model LASER/F is 0.40 and the one derived from the facade density (Equation [3]) is 0.39 . This estimation of the SVF based on the facade density within the pixel also provides satisfying results at district scale and can then be applied over pixels covering larger and more complex areas than just a canyon. However, the estimation of the SVF is sensitive to the size of ground area used at the border of the scene. In fact, the estimation of the facade density is directly linked to the proportion of facade, roof and ground elements. Here, the average street width is used to define the area of ground at the border of the scene.

As previously, the estimation of the total downwelling TIR radiation $\left(R_{T}^{\downarrow}\right)$ using the proposed method is compared to the one simulated by the 3D model for the month of September. The model setup is the same as for the validation over the canyon configurations. Figure 12 presents the validation graph for the entire scene: for $R_{T}^{\downarrow}$ (black circles), $R_{a t}^{\downarrow}$ (dark dots) and $R_{s}^{\downarrow}$ (light dots) along with their 
respective RMSE. This validation shows that very accurate values of $R_{T}^{\downarrow}\left(\mathrm{RMSE}=2.5 \mathrm{~W} \cdot \mathrm{m}^{-2}\right)$ can be retrieved using the proposed method. This graph also points out an overestimation of the atmospheric contribution and underestimation of the scene contribution, both compensating each other leading to a better estimation of the total downwelling TIR radiation. This trend is opposed to what is observed in Figure 6 for basic canyon configurations, where the scene contribution is overestimated while the atmospheric contribution is underestimated. The observed differences may be caused by the fact that the model simulations were performed using a larger scene, to avoid boundary effects. The values corresponding to the validation area were extracted afterward, but still accounting for the effect of the surrounding buildings. Even if the value of interest to proceed with the estimation of the effective emissivity is the total radiation, this should be further investigated.

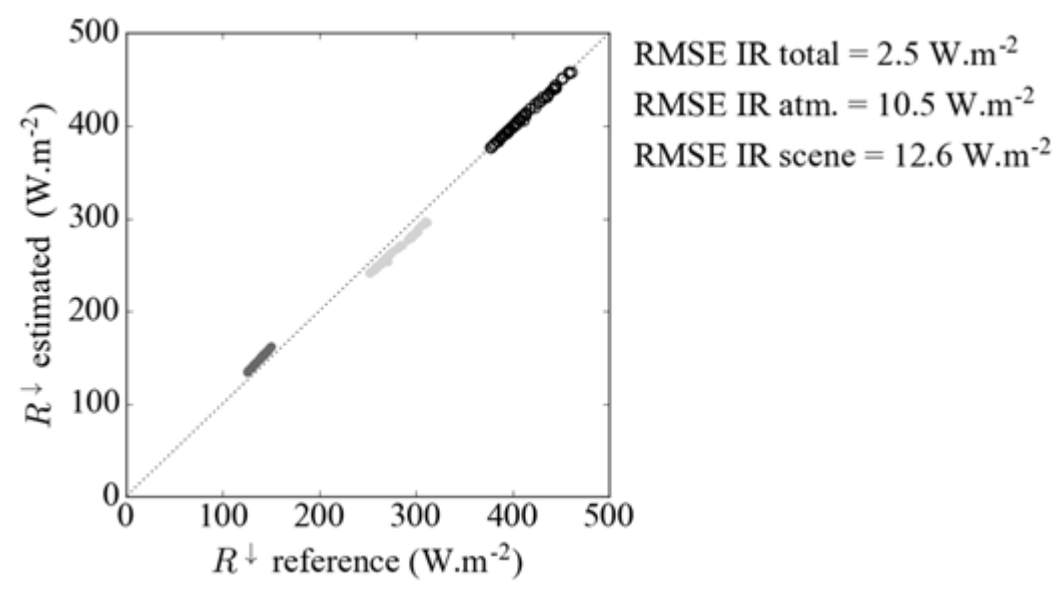

Figure 12. Comparison of estimated and reference total (black circles), atmospheric (dark grey dots) and scene (light grey dots) downwelling TIR radiation for a whole district.

\subsection{Effective Emissivity and LST Derived from ASTER TIR Surface-Leaving Radiance}

\subsubsection{Land Surface Emissivity}

Figure 13 provides two LSE maps derived using the TES algorithm applied over the ASTER image for the three selected districts. The first row of the figure shows a LSE map derived using the total downwelling TIR radiation $\left(R_{T}^{\downarrow}\right)$ derived from the proposed method for each ASTER pixel. The second row shows the LSE map derived using the TOC downwelling TIR, without geometric correction radiation (TOC $R^{\downarrow}$ ). The last row shows the difference between those two maps. The results are displayed for the band $12(9.1 \mu \mathrm{m})$, as it is the band showing the largest differences. The statistics derived for each ASTER band are provided in Table 5. Figure 13 along with Table 5 show that integrating the impact of the surface geometry when deriving LSE from ASTER data highlights the heterogeneity inside the three districts. It also points out that, without correction, the effective emissivity is likely to be overestimated. The largest differences between corrected and non-corrected LSE is observed for the historical center, this district presenting the highest average building height (Table 1). The university district, which has a similar average building height but lower building density, is less affected by the correction. However, the Neudorf district, which presents the highest building density and the lowest average building height, is the district with the lower difference. This confirms that the building height is a key morphological parameter to account for when mapping LSE. 


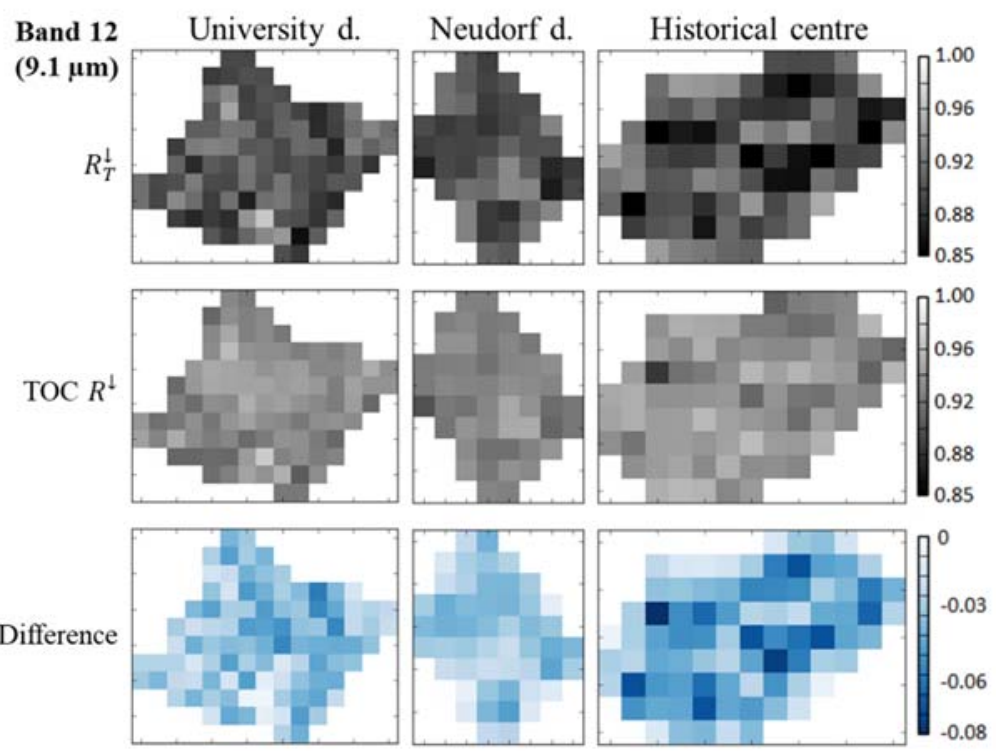

Figure 13. Emissivity maps derived from ASTER band 12 for each district using total downwelling TIR radiation ( $R_{T}^{\downarrow}, 1$ st line), the top of canopy downwelling TIR radiation (TOC $R^{\downarrow}, 2$ nd line) and the difference between both (3rd line).

Table 5. Maximum, mean and standard deviation of the difference between emissivity estimated using total downwelling TIR radiation or top of canopy downwelling TIR radiation for each district (highest values in bold).

\begin{tabular}{cccccccccc}
\hline & \multicolumn{3}{c}{ Max $\varepsilon$ Difference } & \multicolumn{3}{c}{ Mean $\varepsilon$ Difference } & \multicolumn{3}{c}{ Std Dev. $\varepsilon$ Difference } \\
\hline \multirow{2}{*}{ District } & $\begin{array}{c}\text { University } \\
\text { District }\end{array}$ & $\begin{array}{c}\text { Neudorf } \\
\text { District }\end{array}$ & $\begin{array}{c}\text { Historical } \\
\text { Center }\end{array}$ & $\begin{array}{c}\text { University } \\
\text { District }\end{array}$ & $\begin{array}{c}\text { Neudorf } \\
\text { District }\end{array}$ & $\begin{array}{c}\text { Historical } \\
\text { Center }\end{array}$ & $\begin{array}{c}\text { University } \\
\text { District }\end{array}$ & $\begin{array}{c}\text { Neudorf } \\
\text { District }\end{array}$ & $\begin{array}{c}\text { Historical } \\
\text { Center }\end{array}$ \\
\hline Band $8.3 \mu \mathrm{m}$ & $-\mathbf{0 . 0 7}$ & -0.04 & -0.1 & $-\mathbf{0 . 0 1}$ & $-\mathbf{0 . 0 1}$ & $\mathbf{- 0 . 0 1}$ & 0.010 & 0.008 & $\mathbf{0 . 0 1 2}$ \\
Band $8.65 \mu \mathrm{m}$ & -0.04 & -0.04 & $-\mathbf{0 . 0 8}$ & $-\mathbf{0 . 0 2}$ & $-\mathbf{0 . 0 2}$ & $-\mathbf{0 . 0 2}$ & 0.009 & 0.008 & $\mathbf{0 . 0 1 4}$ \\
Band $9.1 \mu \mathrm{m}$ & -0.05 & -0.04 & $-\mathbf{0 . 0 9}$ & -0.03 & -0.03 & $-\mathbf{0 . 0 4}$ & 0.010 & 0.010 & $\mathbf{0 . 0 1 8}$ \\
Band $10.6 \mu \mathrm{m}$ & $-\mathbf{0 . 0 4}$ & -0.02 & $-\mathbf{0 . 0 4}$ & -0.01 & -0.01 & $\mathbf{- 0 . 0 2}$ & 0.007 & 0.003 & $\mathbf{0 . 0 1 0}$ \\
Band $11.3 \mu \mathrm{m}$ & -0.04 & -0.03 & $-\mathbf{0 . 0 6}$ & -0.01 & -0.01 & $\mathbf{- 0 . 0 2}$ & 0.008 & 0.005 & $\mathbf{0 . 0 1 5}$ \\
\hline
\end{tabular}

\subsubsection{Land Surface Temperature}

As in Figure 13, Figure 14 provides two LST maps derived using the TES algorithm over the same ASTER image for the three districts of interest. First, a LST map derived using the total downwelling TIR radiation $\left(R_{T}^{\downarrow}\right)$, then a LST map derived using the TOC-downwelling TIR radiation with no geometric correction (TOC $R^{\downarrow}$ ). The third row shows the difference between those two maps and the last line displays the building footprints, extracted from the BD Topo, colored according to the building height and overlaid on the difference map. This last line aims at highlighting the spatial correlation between larger temperature differences-with and without geometric correction-and building height. Indeed, the largest differences (darker blue) are mostly located close to tall buildings (dark red). The map of the university district shows very low difference values in the southern part (bottom), which is something expected since there is nearly no building. Actually, this area is an urban park with tall trees and grass, and as such should be processed as a vegetated zone. However, as stated in Section 4, urban vegetation coverage processing is out of the scope of this study but should be considered in the future as it can lead to large discrepancies.

As for the LSE, accounting for the impact of the surface geometry highlights the LST heterogeneity inside the districts. The temperature difference statistics for each district are summarized in Table 6. The maximum observed LST difference is $-1.3^{\circ} \mathrm{C}$. However, this image was taken in May and, as shows in the previous section, larger differences could be reached for warmer days and other urban configurations. 


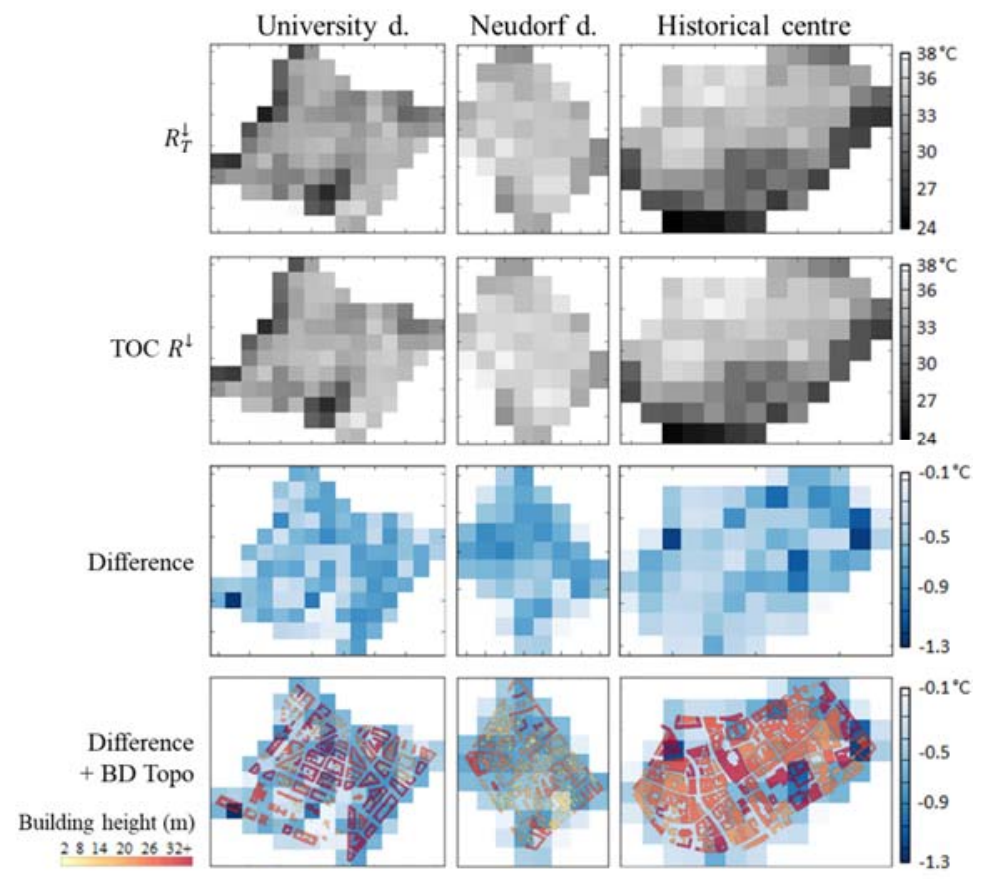

Figure 14. LST maps derived from ASTER for each district using total downwelling TIR radiation ( $R_{T}^{\downarrow}, 1$ st row), top-of-canopy-downwelling TIR radiation (TOC $R^{\downarrow}, 2$ nd row), the difference between both (3rd row) and difference between both + building footprints (4th row).

Table 6. Maximum, mean and standard deviation of the difference between LST estimated using total downwelling TIR radiation or top-of-canopy-downwelling TIR radiation for each district.

\begin{tabular}{cccc}
\hline & University District & Neudorf District & Historical Center \\
\hline Max difference & $-1.3^{\circ} \mathrm{C}$ & $-0.9^{\circ} \mathrm{C}$ & $-1.2^{\circ} \mathrm{C}$ \\
Mean difference & $-0.6^{\circ} \mathrm{C}$ & $-0.6^{\circ} \mathrm{C}$ & $-0.5^{\circ} \mathrm{C}$ \\
Std dev. difference & $0.20^{\circ} \mathrm{C}$ & $0.20^{\circ} \mathrm{C}$ & $0.23^{\circ} \mathrm{C}$ \\
\hline
\end{tabular}

\subsubsection{Comparison with ASTER Global Emissivity Dataset v3}

Finally, the LSE maps produced using the proposed method have been compared with the ASTER GED v3. This dataset is also generated using the TES algorithm but with an improved version combined with a water vapor scaling (WVS) atmospheric correction approach. However, the impact of the surface geometry is not considered during the process. Figure 15 shows the difference maps between the two datasets for band 12 for each district. The statistics derived for each ASTER band are provided in Table 7. As for Figure 13, this confirms the probability of overestimation of the emissivity over urban areas when the surface geometry is not taken into account during the estimation of the LSE. The larger mean differences in all bands are still observed for the historical center (Table 5) where the buildings are the tallest. The differences observed between the results obtained with the proposed method and the ASTER GED v3 are globally larger than the ones presented in Section 5.2.1. Those larger differences may be explained by the different version of the TES used by both methods, especially knowing the sensitivity of this algorithm to the atmospheric correction performed upstream [18,44]. It would then be interesting to test the geometric correction proposed in this study on the improved TES used to generate the ASTER GED v3. 

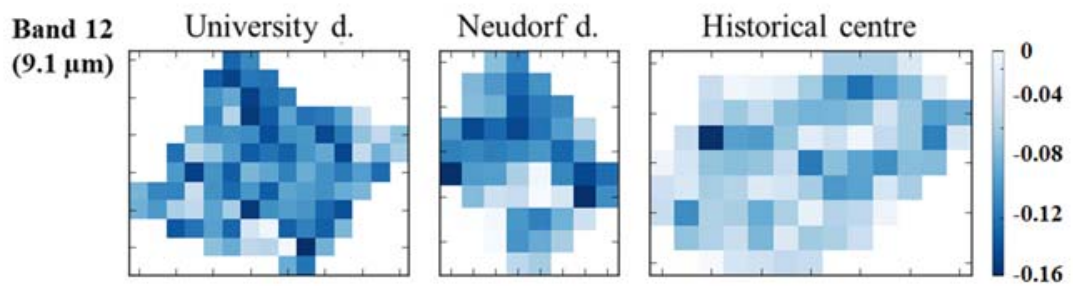

Figure 15. Difference between emissivity maps band $12(9.1 \mu \mathrm{m})$ derived using the proposed method and extracted from the ASTER Global Emissivity Dataset v3.

Table 7. Maximum, Mean and standard deviation of the difference between emissivity estimated using the proposed method and the ASTER Global Emissivity Dataset v3 for each district (highest values in bold).

\begin{tabular}{|c|c|c|c|c|c|c|c|c|c|}
\hline District & \multicolumn{3}{|c|}{ Max $\varepsilon$ Difference } & \multicolumn{3}{|c|}{ Mean $\varepsilon$ Difference } & \multicolumn{3}{|c|}{ Std Dev. $\varepsilon$ Difference } \\
\hline Band $8.65 \mu \mathrm{m}$ & -0.08 & -0.08 & -0.16 & -0.03 & -0.03 & -0.03 & 0.02 & 0.02 & 0.03 \\
\hline Band $9.1 \mu \mathrm{m}$ & -0.08 & -0.08 & -0.16 & -0.05 & -0.05 & -0.06 & 0.02 & 0.02 & 0.03 \\
\hline Band $10.6 \mu \mathrm{m}$ & -0.06 & -0.03 & -0.06 & -0.01 & -0.01 & -0.02 & 0.01 & 0.01 & 0.01 \\
\hline
\end{tabular}

\section{Discussion and Conclusions}

Multispectral TIR satellite radiometers such as ASTER allow for simultaneous retrieval of LSE and LST over urban areas using the TES algorithm. This algorithm is operationally run to generate LSE and LST products from the surface-leaving radiance measured by ASTER and TOC-downwelling TIR radiation simulated using MODTRAN. Because of the urban surface geometrical heterogeneity, the actual amount of TIR radiation received by a pixel is not equal to the TOC-downwelling TIR radiation, which can lead to large discrepancies in LSE and LST estimates over cities. The proposed method accounts for this heterogeneity by integrating the impact of the surface geometry on LSE and LST through estimates of the total downwelling TIR radiation, including atmospheric and scene contributions, and providing it as input of the TES algorithm, in place of the TOC-downwelling TIR radiation. The total downwelling TIR radiation $\left(R_{T}^{\downarrow}\right)$ is derived from surface morphological indicators, such as facade density, and 3D thermo-radiative model simulations. While the surface morphological indicators are used to estimate the SVF, the 3D model simulations are used to account for the non-isothermal behavior of the pixel when estimating the scene emitted TIR radiation. To evaluate the benefits of the proposed method, the estimations are compared to radiances simulated by a reliable 3D model, LASER/F. Various canyon configurations are presented, showing that the proposed method accurately estimates $R_{T}^{\downarrow}$, accounting for the contribution from the atmosphere as well as the scene emission and multiple reflections, with a maximum RMSE of $2.2 \mathrm{~W} \cdot \mathrm{m}^{-2}$. Slight overestimation of the scene contribution and underestimation of the atmospheric contribution are identified for canyons with high buildings $(50 \mathrm{~m})$ and a large street $(50 \mathrm{~m})$. Concerning the estimation of the scene contribution, results highlight the need to account for the non-isothermal behavior of the scene. The different tests show that an isothermal assumption can lead to an overestimation of the contribution of the scene, through overestimation of the scene emission up to $196 \mathrm{~W} \cdot \mathrm{m}^{-2}$ when taking the maximum LST observed over the scene and of $56 \mathrm{~W} \cdot \mathrm{m}^{-2}$ when assuming the surface as flat. The analyses of the difference between TOC-downwelling TIR radiation and the computed $R_{T}^{\downarrow}$ integrating the impact of the surface geometry show variations up to $68 \mathrm{~W} \cdot \mathrm{m}^{-2}$ ( $25 \%$ of the TOC value), which can lead to errors of about 0.05 concerning the surface emissivity and $4{ }^{\circ} \mathrm{C}$ for the surface temperature. The largest differences are observed when the scene contribution significantly impacts the total downwelling 
TIR radiation, like the test periods in March or December, or for canyons with tall buildings and narrow streets.

The same validation of $R_{T}^{\downarrow}$ performed over a real, larger and more complex scene, shows satisfactory results with a maximum error of $2.5 \mathrm{~W} \cdot \mathrm{m}^{-2}$. In this case, slight overestimation of the atmospheric contribution and underestimation of the scene contribution are observed. Even if those errors should be further investigated, the proposed method produces very good $R_{T}^{\downarrow}$ estimates that can be used as inputs of the TES algorithm to retrieve effective emissivity and LST corrected for the surface geometry. Furthermore, even if no strong correlation with morphological indicators could be highlighted, the differences between TOC and $R_{T}^{\downarrow}$ seem to be mostly linked to the height of the building, more than street width. An analysis over three districts of the city of Strasbourg is presented to quantify the impact of this method for a real urban environment based on ASTER images. Even if this analysis does not provide information about the estimation accuracy, it illustrates that the proposed method better highlights district heterogeneity as compared to maps produced by the TES without correction. As for the canyon configurations cases, the largest differences between non-corrected and corrected values are observed in areas with tall buildings while the building density does not seem to significantly affect the results. A comparison with the ASTER GED v3 also confirms those conclusions and leads to the possibility to test the geometric correction proposed in this study on the improved TES used to generate this dataset.

The proposed method, based on geometric characteristics and 3D simulations, accurately estimates the total downwelling TIR radiation. Even if using $R_{T}^{\downarrow}$ to feed the TES algorithm and derive LSE and LST surely improves the estimation, it is necessary to further validate those estimations to confirm this assumption and to evaluate the real benefit of the proposed correction method. This validation requires the use of very high-resolution data, such as airborne data, to quantify the improvement brought by the correction method. Furthermore, as the effect of urban geometry seems to be mostly driven by building height, it would be interesting to extend the tests and apply the method on cities with higher average building height than Strasbourg. However, the correlation between the impact of the surface geometry on the estimations and the surface characteristics should be further investigated. It should also be noted that the proposed method should later account for vegetation structure and properties to better characterize large urban parks. Considering the importance of accounting for the actual geometrical heterogeneity, as demonstrated in this study, and the availability of 3D datasets for more and more cities worldwide, the proposed method can be implemented to provide higher quality LSE and LST products with other existing or forthcoming multispectral TIR sensors.

Author Contributions: L.R. and F.N. conceived and designed the experiments; L.R. performed the experiments and analyzed the data; J.C. contributed to the experiments by helping running the 3D models; L.R. wrote the paper with the help and suggestions of F.N. and J.C.

Acknowledgments: This work was supported by the CNES (Centre National d'Etudes Spatiales) through a post-doctoral grant.

Conflicts of Interest: The authors declare no conflict of interest.

\section{Appendix A}

The computer used to run the simulations presented in the results section has eight cores (Intel(R) Xeon (R) CPU E5-2609v2 @ 2.50GHz (two processors * four cores), RAM: 32 Go). Table A1 provides the computation time for each of the four time periods and each case study considering only one orientation, as the computation time is almost the same for a given building height and street width at each of the three orientations. 
Table A1. Computation time in real and CPU time (minutes) for the simulations run for the 9 canyon configurations (orientation $0^{\circ}$ ) for the 4 time periods $(\mathrm{H}=$ building height $(\mathrm{m}), \mathrm{L}=$ street length $(\mathrm{m})$ ).

\begin{tabular}{|c|c|c|c|c|c|c|c|c|}
\hline \multirow{2}{*}{$\begin{array}{l}\text { Case } \\
\text { Study }\end{array}$} & \multicolumn{2}{|c|}{ March (4 Days) } & \multicolumn{2}{|c|}{ June (6 Days) } & \multicolumn{2}{|c|}{ September (5 Days) } & \multicolumn{2}{|c|}{ December (3 Days) } \\
\hline & $\begin{array}{l}\text { Time } \\
\text { (min) }\end{array}$ & $\begin{array}{l}\text { CPU Time } \\
\text { (min) }\end{array}$ & $\begin{array}{l}\text { Time } \\
\text { (min) }\end{array}$ & $\begin{array}{l}\text { CPU Time } \\
\text { (min) }\end{array}$ & Time & $\begin{array}{l}\text { CPU Time } \\
\text { (min) }\end{array}$ & Time & $\begin{array}{l}\text { CPU Time } \\
\text { (min) }\end{array}$ \\
\hline H10_L5 & 4 & 32 & 7 & 56 & 5 & 40 & 3 & 24 \\
\hline H10_L25 & 4 & 32 & 7 & 56 & 6 & 48 & 3 & 24 \\
\hline H10_L50 & 5 & 40 & 9 & 72 & 7 & 56 & 3 & 24 \\
\hline H30_L5 & 9 & 72 & 19 & 152 & 13 & 104 & 7 & 56 \\
\hline H30_L25 & 11 & 88 & 19 & 152 & 15 & 120 & 7 & 56 \\
\hline H30_L50 & 13 & 104 & 22 & 176 & 17 & 136 & 9 & 72 \\
\hline H50_L5 & 16 & 128 & 25 & 200 & 22 & 176 & 11 & 88 \\
\hline H50_L25 & 17 & 136 & 33 & 264 & 25 & 200 & 12 & 96 \\
\hline H50_L50 & 21 & 168 & 35 & 280 & 26 & 208 & 13 & 104 \\
\hline
\end{tabular}

\section{References}

1. McMichael, A.J. The urban environment and health in a world of increasing globalization: Issues for developing countries. Bull. World Health Organ. 2000, 78, 1117-1126. [CrossRef] [PubMed]

2. Sigman, R.; Hilderink, H.; Delrue, N.; Braathen, N.A.; Leflaive, X. OECD Environmental Outlook to 2050. OECD Environ. Outlook 2012. [CrossRef]

3. Alexander, R.H.; Bowden, L.W.; Marble, D.F.; Moore, E.G. Remote sensing of urban environments. Remote Sens. Environ. 1999, 117, 1-2. [CrossRef]

4. Voogt, J.A.; Oke, T.R. Thermal remote sensing of urban climates. Remote Sens. Environ. 2003, 86, 370-384. [CrossRef]

5. Weng, Q. Thermal infrared remote sensing for urban climate and environmental studies: Methods, applications, and trends. ISPRS J. Photogramm. Remote Sens. 2009, 64, 335-344. [CrossRef]

6. Seto, K.C.; Christensen, P. Remote sensing science to inform urban climate change mitigation strategies. Urban Clim. 2013, 3, 1-6. [CrossRef]

7. Briottet, X.; Chehata, N.; Oltra-Carrio, R.; Le Bris, A.; Weber, C. Optical Remote Sensing in Urban Environments. In Land Surface Remote Sensing in Urban and Coastal Areas; Elsevier: New York, NY, USA, 2016; ISBN 9780081017678.

8. Rasul, A.; Balzter, H.; Smith, C.; Remedios, J.; Adamu, B.; Sobrino, J.; Srivanit, M.; Weng, Q. A Review on Remote Sensing of Urban Heat and Cool Islands. Land 2017, 6, 38. [CrossRef]

9. Nichol, J.E. High-resolution surface temperature patterns related to urban morphology in a tropical city: A satellite-based study. J. Appl. Meteorol. 1996, 35, 135-146. [CrossRef]

10. Voogt, J.A.; Oke, T.R. Complete urban surface temperatures. J. Appl. Meteorol. 1997, 36, 1117-1132. [CrossRef]

11. Coret, L.; Briottet, X.; Kerr, Y.H.; Chehbouni, G. Directional effect on change of spatial scale over heterogeneous surface in thermal infrared remote sensing. In Proceedings of the Remote Sensing For Agriculture, Ecosystems, And Hydrology III (SPIE), Toulouse, France, 28 January 2002; Owe, M., DUrso, G., Eds.; SPIE: Florence, Italy, 2002; Volume 4542, pp. 141-151.

12. Danilina, I.; Gillespie, A.; Balick, L.; Mushkin, A.; Smith, M.; Neal, M. Subpixel roughness effects in spectral thermal infrared emissivity images. In Proceedings of the First Workshop on Hyperspectral Image and Signal Processing: Evolution in Remote Sensing, Grenoble, France, 26-28 August 2009; INFONA: Grenoble, France, 2009; pp. 1-4.

13. Lagouarde, J.; Hénon, A.; Kurz, B.; Moreau, P.; Irvine, M.; Voogt, J.; Mestayer, P. Modelling daytime thermal infrared directional anisotropy over Toulouse city centre. Remote Sens. Environ. 2010, 114, 87-105. [CrossRef]

14. Lagouarde, J.-P.; Hénon, A.; Irvine, M.; Voogt, J.; Pigeon, G.; Moreau, P.; Masson, V.; Mestayer, P. Experimental characterization and modelling of the nighttime directional anisotropy of thermal infrared measurements over an urban area: Case study of Toulouse (France). Remote Sens. Environ. 2012, 117, 19-33. [CrossRef]

15. Yang, J.; Sing, M.; Menenti, M.; Nichol, J. Study of the geometry effect on land surface temperature retrieval in urban environment. ISPRS J. Photogramm. Remote Sens. 2015, 109, 77-87. [CrossRef] 
16. Gillespie, A.; Rokugawa, S.; Matsunaga, T.; Cothern, J.S.; Hook, S.; Kahle, A.B. A temperature and emissivity separation algorithm for Advanced Spaceborne Thermal Emission and Reflection Radiometer (ASTER) images. IEEE Trans. Geosci. Remote Sens. 1998, 36, 1113-1126. [CrossRef]

17. Sabol, D.E.; Gillespie, A.R.; Abbott, E.; Yamada, G. Field validation of the ASTER Temperature-Emissivity Separation algorithm. Remote Sens. Environ. 2009, 113, 2328-2344. [CrossRef]

18. Oltra-carrió, R.; Cubero-castan, M.; Briottet, X.; Sobrino, J.A. Analysis of the Performance of the TES Algorithm Over Urban Areas. IEEE Trans. Geosci. Remote Sens. 2014, 52, 6989-6998. [CrossRef]

19. Berk, A.; Bernstein, L.S.; Robertson, D.C. MODTRAN: A Moderate Resolution Model for LOWTRAN 7; Spectral Sciences Inc.: Burlington MA, USA, 1989.

20. Gastellu-Etchegorry, J.-P.; Yin, T.; Lauret, N.; Cajgfinger, T.; Gregoire, T.; Grau, E.; Feret, J.-B.; Lopes, M.; Guilleux, J.; Dedieu, G.; et al. Discrete Anisotropic Radiative Transfer (DART 5) for Modeling Airborne and Satellite Spectroradiometer and LIDAR Acquisitions of Natural and Urban Landscapes. Remote Sens. 2015, 7, 1667-1701. [CrossRef]

21. Krayenhoff, E.S.; Voogt, J.A. A microscale three-dimensional urban energy balance model for studying surface temperatures. Bound. Layer Meteorol. 2007, 123, 433-461. [CrossRef]

22. Kastendeuch, P.P.; Najjar, G. Simulation and validation of radiative transfers in urbanised areas. Sol. Energy 2009, 83, 333-341. [CrossRef]

23. Musy, M.; Malys, L.; Morille, B.; Inard, C. The use of SOLENE-microclimat model to assess adaptation strategies at the district scale. Urban Clim. 2015, 14, 213-223. [CrossRef]

24. Bruse, M. ENVI-met 3.0: Updated Model Overview. 2004. Available online: http://www.envi-met.net/ documents/papers/overview30.pdf (accessed on 27 February 2018).

25. Martin, E.; Gastellu-Etchegorry, J.-P.; Dhalluin, R. Model intercomparison for validating the 2003 DART Model. In Proceedings of the IEEE International Geoscience and Remote Sensing Symposium, Toulouse, France, 21-25 July 2003; Volume 5, pp. 3272-3274. [CrossRef]

26. Yaghoobian, N.; Kleissl, J.; Krayenhoff, E.S. Modeling the thermal effects of artificial turf on the urban environment. J. Appl. Meteorol. Climatol. 2010, 49, 332-345. [CrossRef]

27. Gros, A.; Bozonnet, E.; Inard, C. Modelling the radiative exchanges in urban areas: A review. Adv. Build. Energy Res. 2011, 5, 163-206. [CrossRef]

28. Maggiotto, G.; Buccolieri, R.; Santo, M.A.; Leo, L.S.; Di Sabatino, S. Validation of temperature-perturbation and CFD-based modelling for the prediction of the thermal urban environment: The Lecce (IT) case study. Environ. Model. Softw. 2014, 60, 69-83. [CrossRef]

29. Azam, M.-H.; Morille, B.; Bernard, J.; Musy, M.; Rodriguez, F. A new urban soil model for SOLENE-microclimat: Review, sensitivity analysis and validation on a car park. Urban Clim. 2017. [CrossRef]

30. Kastendeuch, P.P.; Najjar, G.; Colin, J. Thermo-radiative simulation of an urban district with LASER/F. Urban Clim. 2017, 21, 43-65. [CrossRef]

31. JPL. ASTER Higher-Level Product User Guide, Version 2.0, JPL D-20062; JPL: Pasadena, CA, USA, 2001.

32. Groleau, D.; Mestayer, P.G. Urban Morphology Influence on Urban Albedo: A Revisit with the Solene Model. Bound. Layer Meteorol. 2013, 147, 301-327. [CrossRef]

33. Bernabé, A.; Bernard, J.; Musy, M.; Andrieu, H.; Bocher, E.; Calmet, I.; Kéravec, P.; Rosant, J.M. Radiative and heat storage properties of the urban fabric derived from analysis of surface forms. Urban Clim. 2015, 12, 205-218. [CrossRef]

34. Institut Geographique National. BD TOPO ${ }^{\circledR}$ Version 2.1, Descriptif de Contenu; Institut Geographique National: Saint Mande, France, 2014.

35. Hulley, G.C.; Hook, S.J.; Abbott, E.; Malakar, N.; Islam, T.; Abrams, M. The ASTER Global Emissivity Dataset (ASTER GED): Mapping Earth's emissivity at 100 meter spatial scale. Geophys. Res. Lett. 2015, 42, 7966-7976. [CrossRef]

36. Hulley, G.C.; Hook, S.J. Intercomparison of versions 4, 4.1 and 5 of the MODIS Land Surface Temperature and Emissivity products and validation with laboratory measurements of sand samples from the Namib desert, Namibia. Remote Sens. Environ. 2009, 113, 1313-1318. [CrossRef]

37. Malys, L.; Musy, M.; Inard, C. A hydrothermal model to assess the impact of green walls on urban microclimate and building energy consumption. Build. Environ. 2014, 73, 187-197. [CrossRef] 
38. Roupioz, L.; Kastendeuch, P.; Najjar, G.; Landes, T.; Nerry, F.; Colin, J.; Luhahe, R. Validation du Modèle Laser/F par des Images Thermiques Dans le cadre de la Campagne Bio-Climatologique sur Strasbourg. In Proceedings of the Actes du 29ème Colloque de l'Association Internationale de Climatologie (AIC), Besançon, France, 4-7 July 2016.

39. Masson, V. A physically-based scheme for the urban energy budget in atmospheric models. Bound. Layer Meteorol. 2000, 94, 357-397. [CrossRef]

40. Kusaka, H.; Kondo, H.; Kikegawa, Y.; Kimura, F. A simple single-layer urban canopy model for atmospheric models: Comparison with multi-layer and slab models. Bound. Layer Meteorol. 2001, 101, 329-358. [CrossRef]

41. Wang, Z.-H.; Bou-Zeid, E.; Smith, J.A. A coupled energy transport and hydrological model for urban canopies evaluated using a wireless sensor network. Q. J. R. Meteorol. Soc. 2013, 139, 1643-1657. [CrossRef]

42. Najjar, G.; Colin, J.; Kastendeuch, P.; Ngao, J.; Saudreau, M.; Landes, T.; Ameglio, T.; Luhahe, R.; Guillemin, S.; Schreiner, G.; et al. A three years long fieldwork experiment to monitor the role of vegetation on the urban climate of the city of Strasbourg, France. In Proceedings of the ICUC9, 9th International Conference on Urban Climate Jointly with 12th Symposium on the Urban Environment, Toulouse, France, 15 May 2015; p. 6.

43. Ringenbach, N. Bilan Radiatif et Flux de Chaleur en Climatologie Urbaine: Mesures, Modélisation et Validation sur STRASBOURG. Ph.D. Thesis, Louis Pasteur University, Strasbourg, France, 2004.

44. Pérez-Planells, L.; Valor, E.; Coll, C.; Niclòs, R. Comparison and evaluation of the TES and ANEM algorithms for land surface temperature and emissivity separation over the area of Valencia, Spain. Remote Sens. 2017, 9, 1251. [CrossRef]

(C) 2018 by the authors. Licensee MDPI, Basel, Switzerland. This article is an open access article distributed under the terms and conditions of the Creative Commons Attribution (CC BY) license (http:/ / creativecommons.org/licenses/by/4.0/). 